\title{
Non-Parametric Probability Distribution Data Type
}

National Cancer Institute

\section{Source}

National Cancer Institute. Non-Parametric Probability Distribution Data Type. NCI

Thesaurus. Code C95671.

A data type comprised of a set of uncertain probalistic values in histogram format. 